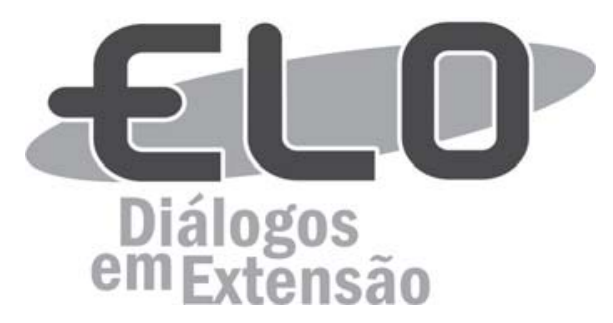

\title{
Aquicultores do sul de Goiás: uma proposta de Plano de Negócio
}

\author{
Lissandra Andréa Tomaszewski ${ }^{1}$; Sara Pereira \\ Silva ${ }^{2}$; Marcos Mateus dos Santos Silva
}

\begin{abstract}
Resumo: Este projeto teve como objetivo apresentar um Plano de Negócios para cooperativas do setor de aquicultura. Inicialmente foram levantados dados sobre aquicultura, enfatizando a piscicultura no Brasil, e, em seguida, na região Sul do Estado de Goiás. Além disso, se averiguou a existência de Cooperativas e/ou Arranjos Produtivos Locais (APL's) na região, a fim de propor parcerias para fortalecer esses projetos junto a Políticas Públicas. O propósito foi o de ressaltar a importância da aquicultura, da agricultura familiar e do planejamento em cooperativas no desenvolvimento de seus produtos, além da utilização de ferramentas que auxiliem na gestão dos empreendimentos. Obteve-se como resultado a confecção do Plano de Negócio, com a aplicação da ferramenta de análise SWOT. Assim, concluiu-se que as ferramentas de gestão auxiliam de forma relevante no planejamento dos empreendimentos.
\end{abstract}

Palavras-chave: Empreendedorismo. Piscicultura. Gestão.

Área Temática: Cooperativismo.

\section{Aquicultores from the south of Goiás: a Business Plan proposal}

Abstract: This project aimed to present a Business Plan designed for aquaculture cooperatives. First of all, data about aquaculture was collected, emphasizing fish farming in Brazil, and then in the southern state of Goiás. In addition, it was aimed to verify the existence of cooperatives and/or Local Productive Arrangements (LPA's) in the region, in order to propose partnerships to strengthen these projects beside Public Policies. The purpose was to emphasize the importance of aquaculture and family farming and planning in cooperatives in the development of their products, as well as the use of tools that help in the management of the enterprises. The obtained results were the preparation of the business plan, applying the SWOT analysis tool. Thus, it was concluded that the management tools help in a relevant way the planning of undertakings.

Keywords: Entrepreneurship. Pisciculture. Management.

\section{Los agricultores de Goiás sur: un proyecto de Plan de Negocio}

Resumen: Este proyecto tuvo como objetivo presentar un Plan de Negocios desarrollado para cooperativas del sector de acuacultura. Inicialmente, fueron colectados datos sobre acuacultura, dándole énfasis a piscicultura en Brasil, y luego, en la región sur del Estado de Goiás. Además, se verificó la existencia de cooperativas y/ o Arreglos Productivos Locales (APL's) en la región, con la finalidad de se proponer asociaciones para fortalecer los proyectos junto a políticas públicas. El objetivo era poner de relieve la importancia de la acuicultura, de la agricultura y de la planificación familiar en las cooperativas en el desarrollo de sus productos, y el uso de herramientas que ayudan en la gestión de las empresas. Se obtuvo como resultado la elaboración

\footnotetext{
${ }^{1}$ Orientadora - E-mail lissandraandrea@gmail.com,Instituto de Ensino Superior - ILES/ULBRA Avenida Beira Rio, 1.001 Bairro Nova Aurora CEP $75522-330$ Itumbiara-GO. Fone (064) 981194063

${ }^{2}$ Graduanda do Curso de Engenharia de Produção - E-mail sara_pereira@windowslive.com

${ }^{3}$ Graduando do Curso de Engenharia de Produção - E-mail mmateus.engineering@yahoo.com.brat
} 
del plan de negocios, con la aplicación de la herramienta análisis SWOT. Así, se concluyó que las herramientas de gestión son una manera relevante de planeamiento para emprendimientos.

Palabras clave: Emprendimiento. Piscicultura. Gestión.

\title{
Introdução
}

As cooperativas surgiram mediante as necessidades de agricultores, artesões e operários se organizarem para se defenderem das situações do mercado. Logo, pode-se mencionar que a cooperativa é um sistema econômico-social conduzido por meio de bases democráticas, com o trabalho realizado a partir de ajuda mútua, importando-se sempre em cumprir as necessidades econômicas de todos os cooperados (ETGETO et al; 2005).

\begin{abstract}
O cooperativismo na pesca tem como alvo organizar a produção e comercialização dos pescadores. Ele serve também para a conscientização política e social da classe pesqueira, através de uma gestão organizada e transparente. Desta forma, o papel das cooperativas é de organizar economicamente a classe, suprindo os elos da cadeia produtiva da pesca e aumentando as oportunidades de geração de renda e trabalho para os pescadores e seus familiares. Para isso, uma entidade com cooperados é essencial para que os pescadores busquem um preço justo pelo pescado que capturam; oficialmente e adquirindo maior valor e poder aquisitivo. (DUPPRÉ; 2011).
\end{abstract}

A partir da necessidade de produzir, processar e comercializar os produtos da agricultura familiar de Itumbiara, município do sul do Estado de Goiás e região, formou-se uma Cooperativa de Pesca. Dentre os projetos desenvolvidos pela Cooperativa estão o comércio do couro da tilápia, espécie em abundância na região, e o mercado de alimentos derivados da carne do peixe, este como uma atividade promissora no mercado de congelados. Mesmo que esses projetos já tenham sido testados, obtendo resultados positivos, a empresa não possui um eficiente estudo de mercado, tampouco recursos financeiros suficientes para atender à demanda. Diante disso, vê-se a necessidade de um planejamento de negócios que auxilie na alavancagem do empreendimento.

\section{Aquicultura}

Segundo Oliveira (2009), a aquicultura é uma ciência que atua com cultivo, confinamento e domínio de organismos predominantemente aquáticos, a mesma é considerada uma atividade multidisciplinar, trabalhando com a produção de diversos tipos de organismos aquáticos. Dias e Mariano (2015) definem a aquicultura como sendo uma atividade agropecuária que mais cresce no país, onde há a piscicultura na produção de peixes.

Na Figura 1, é possível notar a produção de pescado (continental e marinha) relativa a cada região do país podendo também destacar o aumento produtivo entre os anos de 2010 e 2011.

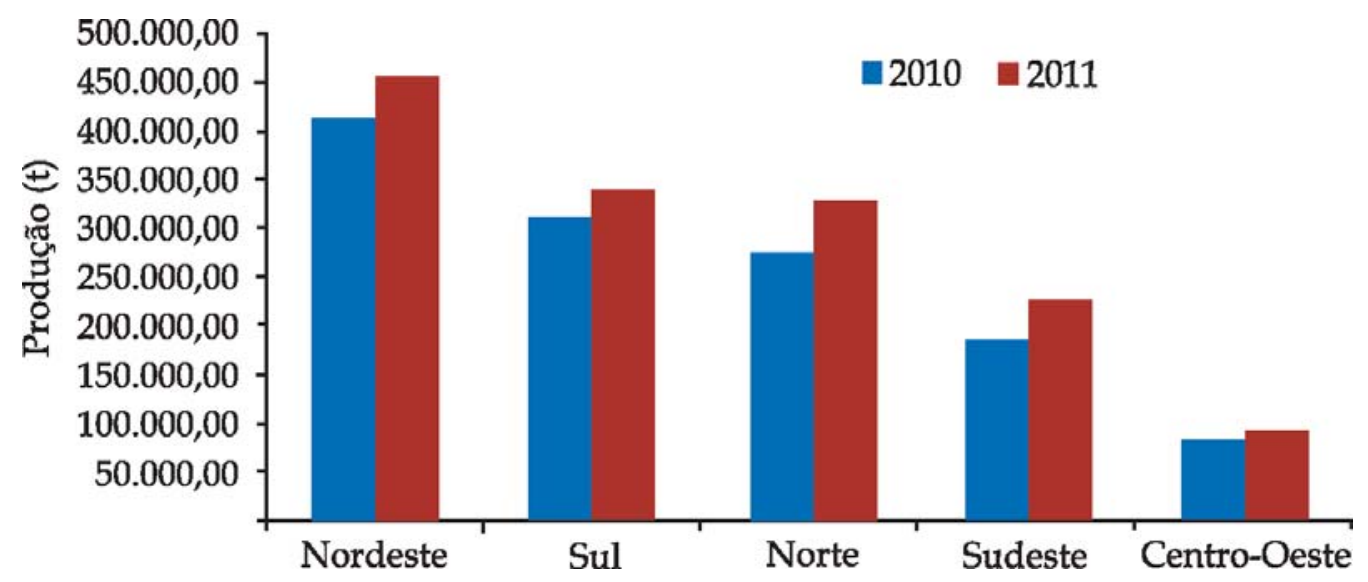

Figura1 - Produção de pescado nacional 2010 e 2011 por região

Fonte: Ministério do Desenvolvimento, Indústria e Comércio Exterior - MDIC (2011). 


\section{Piscicultura no Brasil}

A piscicultura se caracteriza como o cultivo de peixes, o que engloba a preocupação com as instalações, a alimentação e o manejo, a fim de que ocorra o aumento da produção. Com base nos sistemas de cultivo, em algumas partes do mundo existem o domínio genético e o controle total do ambiente de confinamento dos peixes, porém, no Brasil, o trabalho com o domínio genético é recente e os passos estão lentos para chegar ao controle desejado. Existem algumas características impostas para se utilizar uma espécie em cultivo, tais como: i) adaptação ao clima em que será cultivada; ii) crescimento breve; iii) ser, de preferência, onívora; iv) ter uma resistência elevada; v) possuir aceitação do público-alvo (NASCIMENTO; OLIVEIRA, 2010).

Em 1932 a piscicultura no Brasil teve um grande avanço decorrente de estudos para técnicas de indução de hormônios que causam a maturação dos ovos, desova das fêmeas e uma maior produção de espermatozoides dos machos. Já na década de 80, a piscicultura assume características de uma atividade econômica lucrativa, utilizando tecnologias para o avanço de uma produção em escala comercial (PISCICULTURA, 2016). Pode-se observar a seguir, na Figura 2, a determinação de maior produção de cada espécie por região do Brasil.

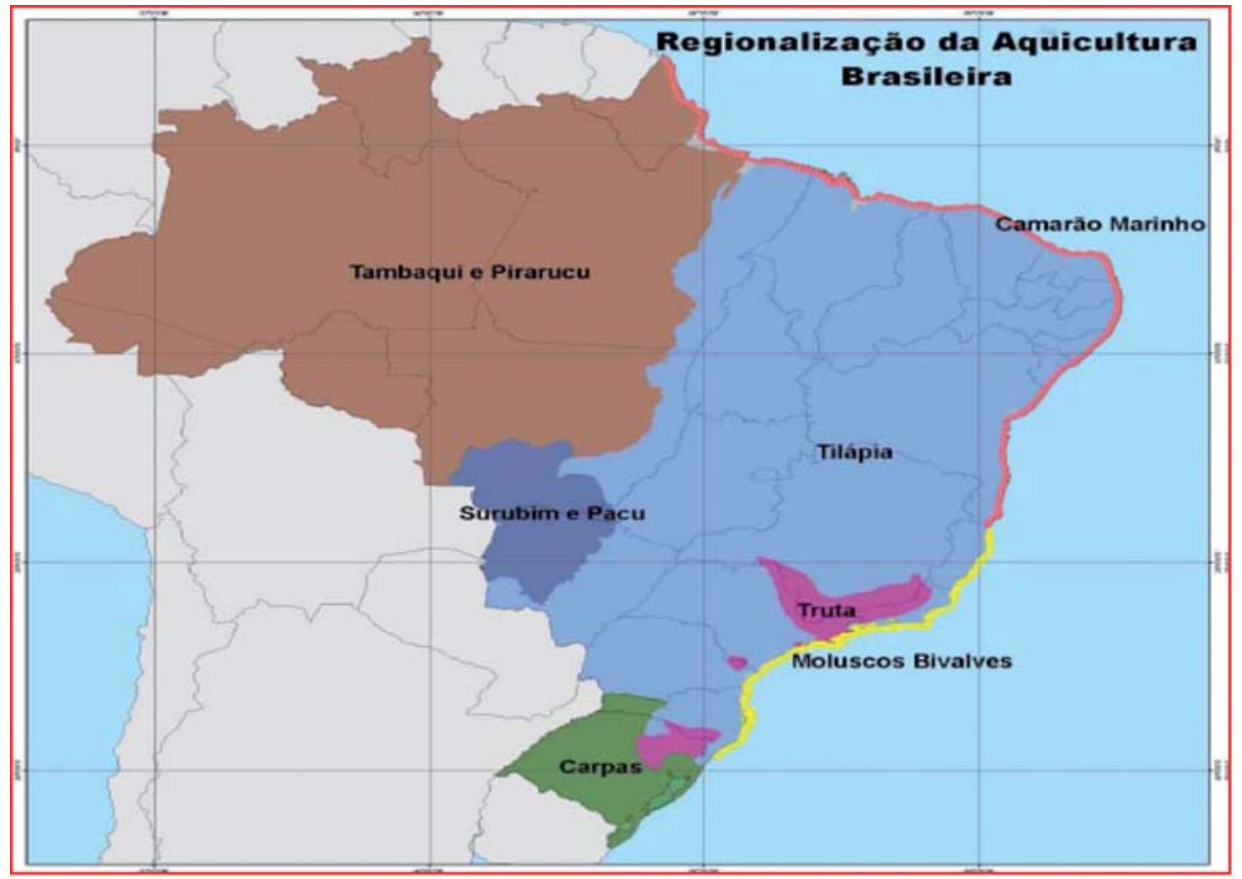

Figura 2 - Regionalização da aquicultura brasileira

Fonte: Borges (2014).

No Brasil a média por habitante/ano no país alcançou $11,17 \mathrm{Kg}$ de produtos provenientes da piscicultura em 2011, crescimento de 14,5\% em relação a 2010. Em 2009 e 2010 o ritmo de crescimento foi de 7,9\%. Em dois anos o crescimento da demanda por peixes e frutos do mar aumentou em média $23,7 \%$. Sendo assim, de acordo com a margem de crescimento e com a soma das importações, atualmente pode-se dizer que os brasileiros já devem consumir $12 \mathrm{Kg} /$ habitante/ano, média mínima recomendada pela OMS (PORTAL BRASIL, 2013).

Em 2013 a produção total de piscicultura no Brasil foi de 392,5 mil toneladas, sendo a região CentroOeste a principal produtora, com a produção de 19,3\% da produção nacional. Em relação aos municípios, a cidade Sorriso-MT produziu 21,5 mil toneladas de peixes em 2013 (PORTAL BRASIL, 2014).

\section{Piscicultura em Goiás}

O Estado de Goiás possui importantes bacias hidrográficas, tais como: Tocantins, Araguaia e Paranaíba, além de características favoráveis a produção de peixes devido à topografia e clima. Em 
2013, a atividade estava em crescimento, mas a elevação dos custos, a estagnação dos preços e a falta de renovação de licenças ambientais trouxeram consequências como a retração de 5,64\% em 2014 com a produção de 21,6 mil toneladas. As espécies mais criadas em 2014 foram a tilápia, representando $34 \%$ da produção total, o pacu e a patinga com $21 \%$ da produção total (RIBEIRO; 2015).

Apesar da quantidade de mananciais hídricos de Goiás, pode-se concluir que o baixo nível de exploração da região são os empecilhos burocráticos encontrados pelo produtor. Segundo dados da Associação Brasileira da Piscicultura (2015), o Estado possui uma alíquota de ICMS de 12\%, a maior do país, enquanto os outros Estados possuem uma alíquota de 0 a 5\%, o que torna a venda interestadual inviável; e, consequentemente, a produção sem demanda. Além disso, o consumo interno é baixo e o Estado sofre com o deficit de frigoríficos, falta de organização da cadeia e necessidade de regularização ambiental.

\section{Cooperativas}

Machado et al. (2006) diz que as cooperativas são organizações em que os cooperados estabelecem entre si uma divisão democrática, de ajuda mútua e com objetivos econômicos e sociais comuns e preestabelecidos. As cooperativas em Goiás relacionadas à aquicultura são: Cooperativa de Pescadores de Uruaçu - COOPERPESCA; Cooperativa Mista Agropecuária de Paraúna - Goiás e Região COOMPAR; Cooperativa de Pesca, Aquicultura e Agricultura Familiar de Goiás - COOPESGO. As principais espécies de peixes nativos e criados em Goiás são: tilápia, tambaqui, pintado e o dourado.

\section{Arranjos Produtivos Locais}

APL's se define como a existência de um conjunto de empresas em torno de uma atividade produtiva principal, que possuem a mesma localização territorial, mantendo vínculos de articulação, interação, aprendizagem e cooperação. A aglomeração, consequentemente, produz algumas vantagens, tais como a proximidade geográfica, trazendo o acesso rápido a matérias-primas, equipamentos e mão de obra, gerando vantagens competitivas ao aumentar as chances de crescimento e sobrevivência das empresas. A inovação e aprendizagem ocorrem pela existência de atividades, ações-e projetos, tantosentre as empresas cooperadas, como também por associações entre outras empresas e instituições técnicas e financeiras (CARDOSO; 2014).

\section{Objetivos}

O objetivo geral deste artigo foi confeccionar um Plano de Negócios para a cooperativa em estudo. Dentre os objetivos específicos estão: i) levantar dados em relação à aquicultura, com ênfase na piscicultura, em nível de Brasil, a fim de obter um diagnóstico com informações pertinentes ao desenvolvimento do setor. Após, o foco será na região sul do Estado de Goiás; ii) averiguar a existência de Cooperativas e/ou Arranjos Produtivos Locais (APL's) na região a fim de propor parcerias para fortalecer estes projetos junto a Políticas Públicas; iii) ressaltar a importância da aquicultura e agricultura familiar em Goiás. Auxiliar a cooperativa no desenvolvimento de seus produtos além de utilizar ferramentas que auxiliarão no planejamento de gestão. O interesse por este estudo surgiu da necessidade de prover a cooperativa e investidores da aquicultura oportunidades de expansão de negócios, já que essa atividade está em contínuo crescimento no Brasil.

De acordo com Portal Matsuda (2016, p.1), em entrevista com o doutor em aquicultura Dr. Fernando Kubitza, "há uma demanda considerável em relação à piscicultura no país. Além disso, apresenta a tilápia, a espécie de maior demanda cultivada no Brasil, com mais de 210 mil toneladas produzidas ao ano". Ainda, ressalta, que a piscicultura é a atividade mais rentável de produção animal. Entende-se, portanto, que há oportunidades de investimentos nesta área. Entretanto,

A atividade encontra-se pouco estruturada no Brasil. Há dificuldade na obtenção de licenças, carência de assistência técnica, manejo inadequado, falta de padronização, insuficiência de pacotes tecnológicos e grande necessidade de capital de giro. Esses mesmos gargalos, porém, podem ser vistos como oportunidades. Uma política de P\&D para espécies promissoras e a modernização e profissionalização do setor podem significar uma inflexão no desenvolvimento do setor no Brasil. (SIDONO et al., 2012, p.422) 
Sidonio et al. (2012) ressaltam que o Brasil, em âmbito mundial, possui a maior reserva de água doce, dispondo de 8 mil km³, superior à Rússia, segunda colocada mundial, dispondo de $4,5 \mathrm{mil} \mathrm{km}^{3}$. Além disso, segundo dados do Ministério da pesca e aquicultura, o país possui um litoral com 7,4 mil km de extensão. "Contudo, o aproveitamento desses recursos para a produção aquícola ainda está muito aquém de seu potencial".

Diante do apresentado, vê-se o quão importante é conhecer o potencial da região Centro-Oeste do Brasil, em específico o Estado de Goiás, onde está inserida a cooperativa em estudo. A região possui um potencial hídrico considerável, que se destaca por ser contemplado com a bacia do Araguaia/ Tocantins e a bacia do Paranaíba. Em algumas localidades, as bacias são utilizadas para produção de energia hidrelétrica, com grande potencial produtivo no ramo aquicultor, porém, pouco explorado (FONSECA; OLIVEIRA, 2007).

Em virtude dos fatos mencionados, foi desenvolvido um estudo de mercado onde se coletou dados que embasaram esta pesquisa. Além disso, a partir de entrevistas com gestores da cooperativa e agregados, iniciou-se o estudo referente ao tema exposto.

\section{Método de trabalho}

A análise deste projeto partiu da necessidade de se desenvolver um Plano de Negócios, colocar em prática ferramentas que auxiliam no processo produtivo e gestão administrativa, a fim de auxiliar a Cooperativa no seu desenvolvimento socioeconômico. Este projeto atende o município de Itumbiara/ Goiás e arredores. A etapa de planejamento surgiu logo após estudos realizados em relação à aquicultura e piscicultura, a piscicultura no Brasil e no Estado de Goiás e os passos para confecção de um Plano de Negócios. Foram realizadas reuniões com representantes da Cooperativa, além de visitas a sede e aos locais de produção. A partir disso, iniciou-se a elaboração do Plano de Negócios, no qual foi feito um levantamento de todas as etapas necessárias para a sua confecção, tais como: a construção da análise de mercado, análise operacional, missão, visão, valores, marketing, entre outras.

A coleta de dados ocorreu a partir de pesquisas quanti-qualitativas, já que todas as informações analisadas foram registradas em forma de relatórios. Uma das técnicas utilizadas na coleta de dados foi o grupo focal, que segundo Dresch, Lacerda e Antunes Júnior (2015), é um importante método para se coletar os dados; essa técnica é de natureza qualitativa, pois busca o entendimento das considerações que um grupo de pessoas tem; por meio de uma experiência, ideia ou evento. O resumo do método de trabalho se encontra no Quadro 1.

Quadro 1 - Método de Trabalho

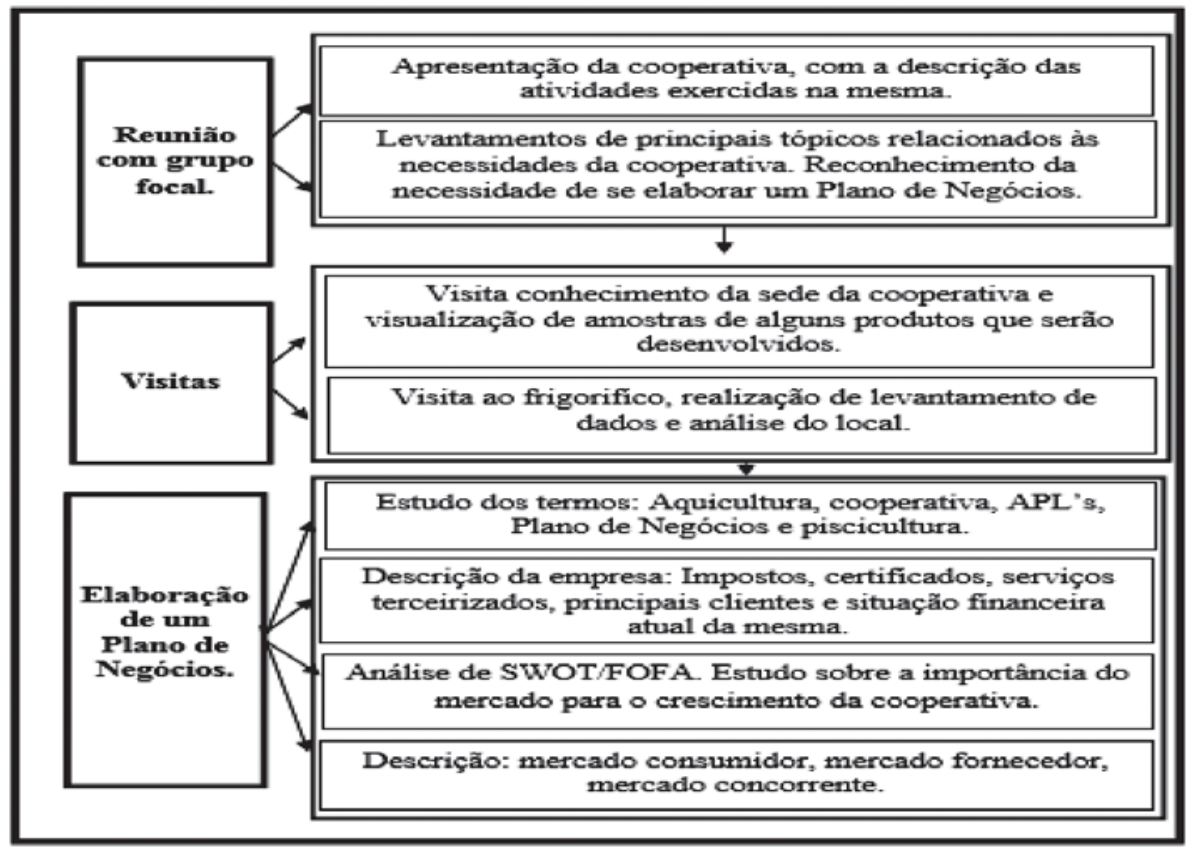

Fonte: Autores (2016). 


\section{Plano de Negócios}

Na concepção de Dornelas (2005), um Plano de Negócio nada mais é que um documento no qual a ideia de um empresário, para seu empreendimento, é transcrita. Dessa forma, tal documento serve como um guia ou roteiro a ser seguido em momentos de decisões estratégicas perante a empresa. Todo empreendedor que visa transformar seu sonho em realidade deveria elaborar um Plano de Negócios.

O Plano de Negócios é a parte fundamental de um processo empreendedor, nele são descritos todos os pontos fortes e fracos do negócio, os elementos internos e externos que podem afetar o empreendimento, o diagnóstico do mercado no qual a empresa se encontra, necessidades futuras, tudo com intuito de mensurar o potencial da empresa. (RAYOL,2007, p.8)

Ainda, de acordo com Dornelas (2005), com este roteiro em mãos a identificação de oportunidades fica mais fácil, devido, dentre outros recursos, a capacidade de calcular a viabilidade de um projeto e a avaliação de riscos. Além disso, a credibilidade do empreendimento será facilmente transmitida pelo plano, acarretando a atração de recursos financeiros.

O presente Plano de Negócios trata de diagnosticar a situação da empresa por intermédio da análise de dados atuais e de dados que são calculados em médio e longo prazo. Uma análise econômicofinanceira visará viabilidade dos projetos propostos pelos cooperados juntamente à diretoria, definindo assim, os pontos pertinentes a serem observados antes da tomada de decisão em relação ao investimento.

\section{Localização}

A cooperativa em estudo se encontra localizada na região Sul do estado de Goiás no município de Itumbiara, obtendo assim uma localização estratégica e benéfica ao ramo em que atua, pois o território é amplamente rico em recursos hídricos.

Na Figura 3 é possível observar que Itumbiara faz divisa entre os estados de Goiás e Minas Gerais e possui como uma das suas principais rodovias a BR 153, a quarta maior do país, o que torna a cidade um grande ponto logístico para exportações. De acordo com o IBGE (2016), Itumbiara possuiu uma população estimada em 101.544 mil habitantes, possuindo uma área territorial de $2.464,510 \mathrm{Km}^{2}$, a mesma foi elevada a município pela lei estadual de número 349, no ano de 1909.

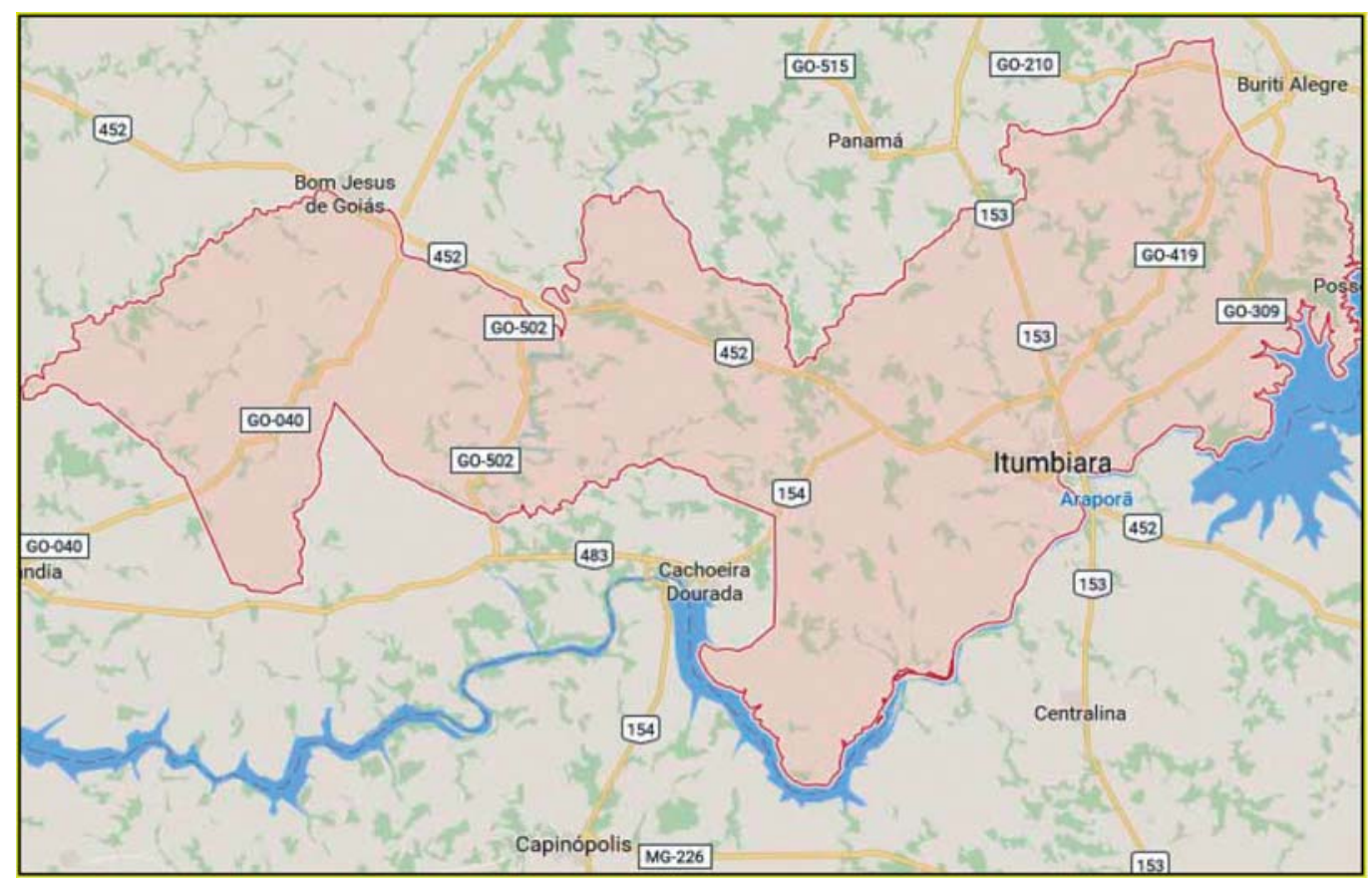

Figura 3 - Mapa de Itumbiara

Fonte: GOOGLE MAPS (2017). 


\section{Direcionamento estratégico}

O direcionamento estratégico é composto basicamente pela visão, missão e os objetivos que a empresa possui. Ter objetivos bem claros faz com que a empresa tenha uma direção a seguir. Esses são os princípios fundamentais e básicos de uma empresa, mesmo que não estejam transcritos em algum lugar é a razão pelo qual todos trabalham em busca de objetivos de interesses comuns. (SEITZ, 2005). De acordo com dados e objetivos da cooperativa em estudo, elaborou-se um direcionamento estratégico.

\section{Visão}

Ser referência para as cooperativas de aquicultura e piscicultura da região sul de Goiás.

\section{Missão}

Oferecer produtos de excelência, buscando a satisfação de clientes, funcionários e parceiros, atuando com responsabilidade social e ambiental, seguindo todas as normas e leis e, assim, garantir um produto de qualidade.

\section{Princípios}

Respeito, sustentabilidade, confiança, trabalho em equipe, responsabilidade social, proatividade e qualidade.

\section{Objetivos e Metas}

- Adquirir uma fábrica de ração própria;

- Expandir a produção de alimentos derivados da carne do peixe;

- Ter um frigorífico com sede própria;

- Ter a licença para comercialização do couro de peixe beneficiado;

- Estruturação da cadeia produtiva do pescado, garantindo agregação de valor em todas as fases da produção;

- Possibilitar o investimento seguro dos produtores na produção, processamento dos produtos e o escoamento da produção;

- Gerar trabalho e renda para pequenos produtores rurais, aquicultores e pescadores artesanais;

- Fornecimento para os mercados institucionais, atendendo as necessidades de alimentos ecologicamente corretos, além de atender a lei federal 11.947 (PAA e PNAE).

É de suma importância estudar e conhecer o mercado em que seu negócio está inserido, perguntas como: "O que é o mercado consumidor?"; "O produto atende as necessidades desse mercado consumidor?"; "Como está o mercado concorrente?"; “Como o seu negócio está situado em relação ao mercado concorrente?"; "Como funciona o seu mercado fornecedor?"; são relevantes a fim de planejar o negócio. A seguir, alguns estudos para esses questionamentos.

\section{Mercado}

O mercado consumidor de pescado no Estado de Goiás é crescente se comparado há anos anteriores; o estado consome em grande parte proteína animal derivada da carne bovina, essa encontrada em grande oferta no mesmo e com preços, muitas vezes, mais acessíveis, ponto destacado inclusive pelo vice-presidente da cooperativa.

Outro ponto em que a cooperativa e todo o mercado goiano fornecedor de pescado encontra dificuldades é que, além da demanda interna não ser altamente satisfatória, é praticamente inviável o fornecimento a consumidores de outro estado, pois em Goiás a taxa de ICMS sobre o peixe gira em torno de $12 \%$ enquanto no restante do país varia de isento a $5 \%$, tornando a concorrência praticamente invencível. O Estado sofre também com poucos frigoríficos destinados ao processamento de pescado, ponto estse tratado pela Associação Brasileira da Piscicultura (2015). 
Portanto, por meio da identificação do mercado no qual a cooperativa está inserida, é necessário que se faça uma análise dele a fim de identificar oportunidades para o negócio, analisar o mercado e levantar informações cruciais para o negócio sobre a economia, os consumidores, os fornecedores e etc. (MENDES, 2013).

\section{Estudo de mercado consumidor}

Por meio desta análise de mercado consumidor será identificado o perfil de consumidor que a cooperativa em estudo precisa atender. Segundo Kotler (2000), compreender as necessidades e os desejos dos clientes não é uma tarefa fácil, pois alguns consumidores têm necessidades e desejos das quais não têm plena consciência ou não conseguem compreender. A Cooperativa precisa identificar esses desejos e necessidades, além de mostrar para o consumidor porque ele deve e precisa consumir seu produto e quais são as vantagens, a fim de alcançar um maior número de consumidores fiéis.

A Cooperativa em estudo já atua na venda de alguns de seus produtos e há uma demanda considerável, visto a dificuldade de divulgação. Hoje, há três tipos de produtos à venda voltados para a piscicultura, são eles: i) carnes de peixes, como pirarucu e tilápia; ii) bolinhos de peixe com mandioca e bolinhos de peixe com quibe; iii) produção de peles de pirarucu e tilápia beneficiadas. Os bolinhos estão sendo comercializados; e observou-se que o produto atendeu as necessidades dos consumidores locais,; a venda do mesmo é realizada no local onde se instalará o frigorífico. Os consumidores, no geral, serão a população de Itumbiara e arredores, além de artesões.

O frigorífico só não se encontra em funcionamento devido à necessidade de alguns documentos que estão sendo providenciados. As peles beneficiadas possuem uma boa projeção para venda, já que se têm consumidores interessados e essas podem ser utilizados na produção de bolsas, cintos, sapatos, dentre outros produtos. Sua comercialização não está sendo efetuada devido à necessidade de regulamentações que estão sendo providenciadas. Pode-se concluir que ambos os produtos oferecem uma projeção satisfatória para a cooperativa.

\section{Estudo do mercado fornecedor}

O mercado fornecedor será aquele que poderá fornecer à empresa matérias-primas, maquinário, mercadorias, equipamentos e qualquer outro tipo de material necessário para o seu funcionamento. Para iniciar e manter o desempenho e atividade empresarial, a empresa dependerá de seus fornecedores e o conhecimento destes fornecedores refletirá ativamente e diretamente nos resultados pretendidos pela empresa (ESCARLATE, 2010).

A relação com o fornecedor deve ser uma relação de parceria, pois ele é o combustível para a empresa. Ressalta-se a importância em ser criterioso na escolha deste, pois a matéria prima oferecida estará relacionada diretamente com a qualidade final do produto. Diante disso, há algumas questões a se fazer, como por exemplo: i) Quais serão seus fornecedores?; ii) Onde eles estão?; iii) Qual a sua capacidade de fornecimento?; iv) Quais serão as condições de venda?; v) Quais serão as alternativas de fornecimento caso seu fornecedor falhe?. Em relação aos outros fornecedores é preciso analisar qual oferece o melhor preço e com a qualidade desejada, pois se o preço do fornecedor for muito alto, a mercadoria poderá ficar muito cara e inacessível ao mercado consumidor, e se a qualidade do fornecedor cair, a qualidade cairá também, sendo assim, o consumidor buscará melhores opções com uma maior qualidade (CAVASOTTO, 2009).

A cooperativa em estudo tem sua produção inteiramente voltada à comercialização de derivados dos peixes pirarucu e tilápia, esses podem ser classificados como sua matéria prima principal. Ambos são adquiridos de associados, o que torna a ligação entre fornecedor e empresa mais forte ainda, porque os dois aspiram o crescimento; tanto individual quanto em conjunto. Na produção de bolinhos de peixe utilizam-se insumos, como: alho, cebola, pimenta, outros temperos e alimentos; esses podem ser adquiridos em supermercados e feiras, podendo ser encontrados, inclusive, em atacado. Já na produção de peles beneficiadas, será utilizada uma formulação de produtos químicos, que deverão ser fornecidos por uma empresa especializada e autorizada de acordo com as normas exigidas em vigor.

\section{Estudo do mercado concorrente}

O estudo de mercado concorrente é o processo onde se lista as principais empresas e produtos concorrentes, realizando uma comparação entre elas e com o seu produto. Observando a concorrência 
é possível identificar as deficiências e as vantagens ao determinar os possíveis pontos fracos e fortes do ramo e atividade do negócio. Além disso, é possível avaliar o produto da concorrência e observar os pontos negativos e positivos. É necessário trabalhar com afinco nessas avaliações para vender um produto com qualidade superior, com um diferencial e também, para destacar seu produto no mercado. (KLEBIS, 2012).

Observa-se que, no município de Itumbiara e região, não se encontra um grande mercado concorrente neste ramo, principalmente pela cultura da região, em relação ao consumo de peixes e derivados estar tendo um despertar e um crescimento na procura por agora. Atualmente, na região sul de Goiás, se encontra as seguintes cooperativas relacionadas à aquicultura: Cooperativa de Pescadores de Uruaçu - COOPERPESCA; Cooperativa Mista Agropecuária de Paraúna - Goiás e Região - COOMPAR; Cooperativa de Pesca, Aquicultura e Agricultura Familiar de Goiás - COOPESGO. A cooperativa em questão, comparada as outras citadas acima, tem um grande diferencial em se preocupar com a utilização de todas as partes do peixe, transformando o que seria descartado em produto. Além de agregar valor onde não havia, a Cooperativa auxilia também no meio ambiente.

\section{Análise SWOT}

A fim de realizar um levantamento de fatores que podem influenciar o andamento do negócio, utilizou-se a análise SWOT.

Criada por Kenneth Andrews e Roland Christensen, professores da Harvard Bussines School, e posteriormente aplicada por numerosos acadêmicos, a análise SWOT estuda a competitividade de uma organização, segundo quatro variáveis: strengths (forças), weaknesses (fraquezas), opportunities (oportunidades) e threats (ameaças). Através destsa metodologia, poderia fazer-se a inventariação das forças e fraquezas da empresa, das oportunidades e ameaças do meio envolvente e do grau de adequação entre elas. (RODRIGUES; et al, 2005, p.489)

A Análise SWOT é uma ferramenta constantemente usada em diversos ramos de negócios e empreendimentos. Por intermédio dela, é feito um mapeamento da empresa, no qual demonstra tanto os pontos fortes e benéficos à empresa quanto as adversidades e os pontos a melhorar, deixando as falhas claras e evidentes para uma possível correção. A mesma pode ser dividida em dois pontos principais: o ambiente interno e o ambiente externo. O primeiro ambiente leva em consideração apenas características essenciais à própria empresa, fatores ligados a parte interna da empresa, enquanto, o segundo ambiente, leva em consideração fatores que estão fora do controle interno da empresa. (BASTOS, 2014).

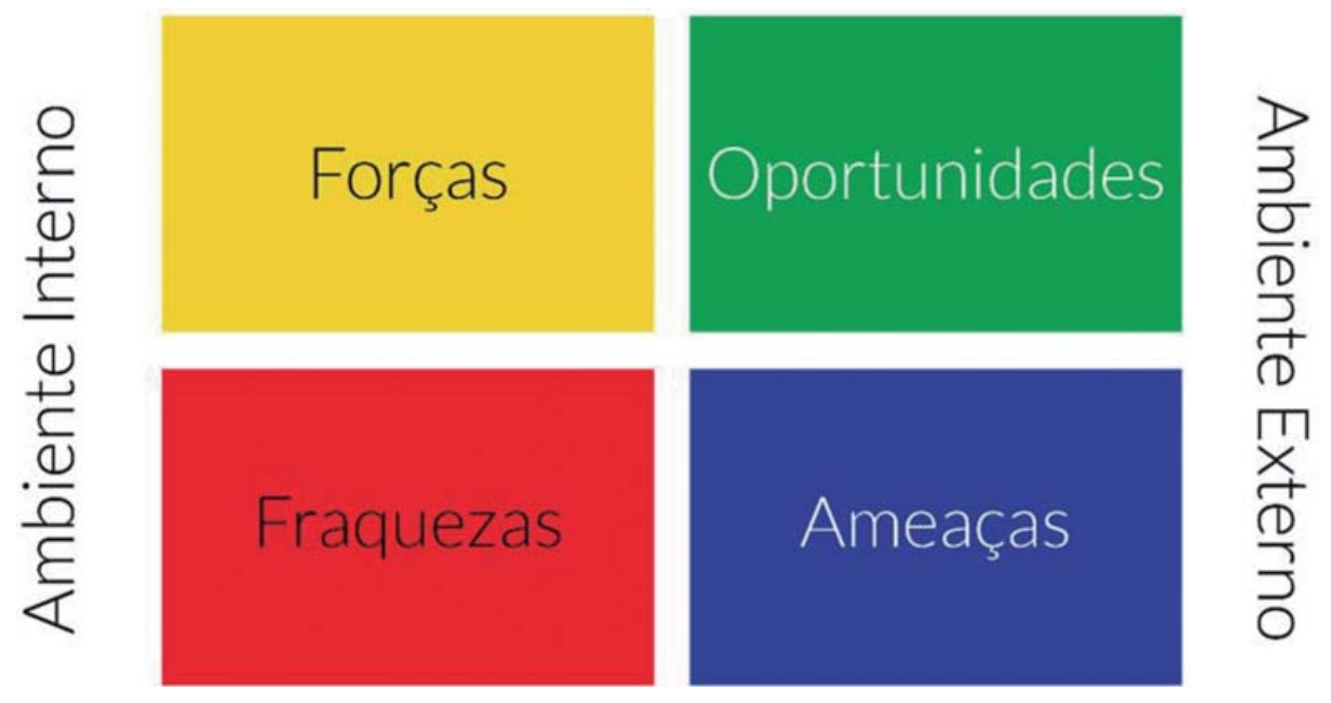

Figura 4 - Modelo de matriz SWOT

Fonte: Paulillo (2016) . 
A ferramenta SWOT torna-se indispensável para se ter um bom desenvolvimento empresarial, atuando no gerenciamento organizacional para otimizar os recursos empresariais (MEDEIROS et al, 2010).

\section{Resultados e discussões}

De acordo com a análise feita, pode-se dizer que esse tipo de empreendimento é viável economicamente e auto sustentável, visto que, a partir de um bom planejamento e apoio financeiro nas políticas públicas, se obtém uma variedade de produtos; agregando, assim, valor à matéria-prima. Os resultados encontrados a partir da análise SWOT, descritas no Quadro 2, confirmam a necessidade de investimento neste setor.

Quadro 2 - Resultados da análise SWOT

\begin{tabular}{l} 
AMBIENTE INTERNO \\
\hline \multicolumn{1}{c}{ PONTOS FORTES } \\
O engajamento dos cooperados em manter um \\
excelente nível de qualidade padrão aos clientes; \\
Trabalho em equipe e o convívio entre os \\
envolvidos torna o feedback mais rápido, \\
facilitando, assim, a melhoria nos processos, na \\
qualidade e na produtividade; \\
O relacionamento direto entre os cooperados e \\
clientes, que faz com que o retorno do cliente, \\
em relação ao produto, seja rápido e direto.
\end{tabular}

\section{PONTOS FRACOS}

Não há um foco em cada projeto separadamente, isto é, estão trabalhando em todos ao mesmo tempo;

Como o empreendimento trata-se de uma novidade no seu ponto comercial, não existe um engajamento dos clientes à cooperativa;

Falta de investimento no marketing;

Há falta de controle e definição dos custos e ganhos de cada produto;

Praticamente todo o processo produtivo é realizado de maneira artesanal.

\section{AMBIENTE EXTERNO \\ OPORTUNIDADES}

Devido à falta de empreendimentos do ramo na região, não se tem uma concorrência em potencial;

Alguns produtos já possuem uma grande demanda;

Existe a possibilidade de crédito bancário a empresas do ramo;

Com investimentos e retornos necessários, é possível e desejado pelos cooperados uma modernização na produção com equipamentos que manteriam a qualidade e aumentariam a produtividade bem como a relação custo-benefício.

\section{AMEAÇAS}

Dificuldade em se adquirir a liberação de licenças ambientais devido a política conturbada da cidade;

A principal fornecedora de ração vive um momento de instabilidade, devido a problemas com equipamentos e a formulação da ração;

Tomadas de decisões sem a análise de mercado;

O consumo de peixe não é intrínseco à cultura da população local.

Fonte: Elaborado pelos autores.

Pode-se comparar estes resultados com a situação da piscicultura em Dourados-MS, onde a cadeia produtiva também é composta por pequenos produtores e não há técnicas específicas para atender a demanda, falta de informações e gestão. A estratégia utilizada é a de troca de informações entre eles mesmos. A dificuldade maior está na venda do peixe ao aumentar a produtividade e diminuir os custos, porém, não há incentivo do governo. (DUTRA et al., 2016). Situações como essas são comuns no país, fazendo com que, uma economia crescente, fique estagnada por falta de recursos e planejamento.

\section{Conclusões}

Este trabalho teve como intuito auxiliar uma cooperativa do município de Itumbiara a fim de melhorar o seu gerenciamento,-. Fizemos isso da seguinte forma: definindo pontos fundamentais 
para o seu desenvolvimento, demonstrando a importância de se trabalhar com o planejamento, levantamento de projeções e estudos sobre o mercado em que a mesma está inerida.

Com o estudo realizado viu-se a possibilidade de se formar um APL na região do município de Itumbiara, na interação entre produtores, cooperados, fornecedores e o governo local. De acordo com a análise de dados vê-se o grande potencial que a cooperativa possui, principalmente por já terem consumidores interessados em seus produtos, mas, mesmo assim, se vê a necessidade de desenvolvimento, além do plano de negócio, também de um plano de marketing. Observou-se que um dos grandes empecilhos para o desenvolvimento da cooperativa são os interesses políticos e a burocracia do estado de Goiás. Ademais, a preocupação com a sustentabilidade é fundamental em qualquer ramo ou atividade, e isso poderá influenciar diretamente na renda da cooperativa.

\section{Referências}

ASSOCIAÇÃO BRASILEIRA DA PISCICULTURA. Piscicultura goiana sofre com poucos frigoríficos $e$ altos impostos. Site. 2015. Disponível em: <http://www.peixebr.com.br/piscicultura-goiana-sofre-com-poucos-frigorificos-e-altos-impostos/>. Acesso em: 23 mar. 2016.

BASTOS, Marcelo. Análise SWOT (Matriz) - Conceito e aplicação. Site. Disponível em: <http:// www.portal-administracao.com/2014/01/analise-swot-conceito-e-aplicacao.html>. Acesso em: 20 ago. 2016.

BORGES, Adalmyr Morais. Aquicutura desenvolvimento sustentável: cenário brasileiro. In: XI Feira Nacional do Camarão - FENACAM. Fortaleza, 2014. Anais.... Disponível em: <http://fenacam.com.br/ pdf/fenacam2014/aquicultura / 4-aquicultura-desenvolvimento-sustentavel-cenario-dobrasileiro_adalmyr-borges.pdf>. Acesso em: 24 mar. 2016.

CARDOSO, Univaldo; CARNEIRO, Vânia; RODRIGUES, Édna. APL: Arranjo produtivo local. Série: Empreendimentos coletivos. Brasília: Sebrae, 2014.

CAVASOTTO, Cristina. 2009. Qual a importância do mercado fornecedor. Site. Disponível em: <http:// www.clicrbs.com.br/blog/jsp/default.jsp?source=DYNAMIC, blog. BlogDataServer, get $B \log \& u f=1 \& \operatorname{loc} a l=1 \&$ template $=3948 . d w$ t \& section $=B \log s \& p o s t=237484$ \&blog=793\&coldir=1\&topo=3994.dw>. Acesso em: 10 jun.2016.

DIAS, Marcos Tavares; MARIANO, Wagner. Aquicultura no Brasil: Novas Perspectivas. Aspectos Biológicos, Fisiológicos e Sanitários de Organismos Aquáticos. São Carlos: Pedro \& João Editores, 2015.

DORNELAS, José C. Empreendedorismo Transformando Ideias em Negócios. $2^{\mathrm{a}}$ ed. Rio de Janeiro: Editora Campus, 2005, 3 p.

DUPPRÉ; Maurício. O papel das Cooperativas de Pesca. Site. 2011. Disponível em: <http:// cardumebrasil.blogspot.com.br/2011/03/o-papel-das-cooperativas-de-pesca.html>. Acesso em: 20 ago. 2016.

DUTRA, Fábio Mascarenhas at al. Orientação Para o Mercado: Criando Vantagem Competitiva Para Pequenos Piscicultores. Revista Comunicação \& Mercado. Dourados: UNIGRAN, vol. 05, n. 12. 2016.

DRESCH, Aline; LACERDA, Daniel; ANTUNES JÚNIOR, José A. V. Design Science Research. Método de pesquisa para avanço da ciência e tecnologia. 1. ed. Porto Alegre: Bookman, 2015.

ESCARLATE, L. F. Aprender a Empreender. Brasília: Fundação Roberto Marinho, SEBRAE, 2010.

ETGETO, Anderson et al. Os Princípios do Cooperativismo e as Cooperativas de Crédito no Brasil. Maringa Management. Revista de Ciências Empresariais, v. 2, n.1, p. 7-19, jan. /jun. 2005.

FONSECA, Delmivan A. da; OLIVEIRA, Abadia Maria de. Viabilidade Econômica da Aquicultura do Rio Paranaíba: O Caso da Colônia de Pescadores da Ponte Quinca Mariano. In: I Congresso Brasileiro de Produção de Peixes Nativos de água doce e I Encontro de piscicultores de Mato Grosso do Sul, 2007, Dourados. Anais... Dourados,2007. Disponível em: <http://www.cpao.embrapa.br/ aplicacoes/congressopeixe2007/TRABALHOS/OUTROS/OUTROS_17.pdf> 
GOOGLE MAPS. Itumbiara - Go. 2017. Disponível em: <https://www.google.com.br/maps/place/ It u m bi a ra + - GO / @ - 18.3979115,-49.6584293,10 z / d a ta =! 4 m 5!3 m 4! 1 s 0x94 a 10d6489383995:0xa0d3f8f904066d35!8m2!3d-18.4097245!4d-49.2162908>. Acesso em: 3 abr. 2017.

IBGE. 2017. Site. Goias Itumbiara. Disponível em: <http://cidades.ibge.gov.br/xtras/ perfil.php?lang=\&codmun $=521150 \&$ search $=||$ infogr $\%$ E1ficos:-informa $\%$ E7\%F5es-completas $>$. Acesso em: 3 abr. 2017.

KLEBIS, Tati. Passo a passo como fazer uma análise de mercado. Site. 2012. Disponível em: <http:// www.empresassa.com.br/2012/02/passo-passo-como-fazer-analise-de.html>. Acesso em: 10 jun.2016.

KOTLER; Philip. Administração de Marketing. Tecnologia e Linguística. ed. 10. São Paulo: Prentice Hall, 2000.

MACHADO, B. et al. A importância social e econômica da implantação de cooperativas de materiais recicláveis. In: Encontro Nacional de Engenharia de Produção - ENEGEP. Anais... Fortaleza: ABEPRO, 2006.

MDIC-Ministério da Indústria, Comércio Exterior e Serviços. Boletim estatístico da pesca e aquicultura. Site. 2011. Disponível em: < http://www.mdic.gov.br/busca?searchword=aquicultura \&searchphrase=all >. Acesso em: 30 jun. 2016.

MEDEIROS, Elaine et al. Estudo de caso numa franquia pessoense de uma consultoria de gestão com pessoas: análise SWOT. João Pessoa-PB. V Congresso Norte Nordeste de Pesquisa e Inovação - CONNEP. Anais .... 2010.

MENDES, Ione. O que uma análise de mercado pode fazer para o seu negócio?. Site. 2013. Disponível em: < http://www.profissionaldeecommerce.com.br/o-que-uma-analise-de-mercado-pode-fazer-peloseu-negocio/> Acesso em: 30 maio 2016.

NASCIMENTO, Flávio; OLIVEIRA, Márcia. Noções básicas sobre piscicultura e cultivo em tanques-rede no Pantanal. Empresa Brasileira de Pesquisa Agropecuária Embrapa Pantanal Ministério da Agricultura, Pecuária e Abastecimento 2010. Site. Disponível em: <http://www.cpap.embrapa.br/ publicacoes/online/CAR03.pdf>. Acesso em:1º abr. 2017.

OLIVEIRA, Rafael. O panorama da aquicultura no Brasil: a prática com foco na sustentabilidade. Revista Intertox de Toxicologia, Risco Ambiental e Sociedade, vol.2, nº1, fev. 2009.

PAULILLO; Gustavo. O Agendador. Matriz SWOT: Como fazer a análise de sua empresa. Site. 2016. Disponível em:<http:/ / www.agendor.com.br/blog/matriz-swot-como-fazer/>. Acesso em: 16 ago. 2016.

PISCICULTURA. Gestão no Campo. Site. 2016. Disponível em: <http://www.gestaonocampo.com.br/ biblioteca/piscicultura-3/>. Acesso em: 20 ago. 2016.

PORTAL BRASIL. Consumo de pescado no Brasil aumenta 23,7\% em dois anos. Site. Disponível em: <http:/ /www.brasil.gov.br/economia-e-emprego/2013/10/consumo-de-pescado-no-brasil-aumenta-237-em-dois-anos>. Acesso em: 28 ago. 2016.

PORTAL BRASIL. Maiores produtores de peixes do Brasil não estão no litoral e sim no Centro-Oeste, mostra IBGE. Site Brasil. 2014. Disponível em: <http://www.brasil.gov.br/economia-e-emprego/ 2014/12/ maiores-produtores-de-peixes-do-brasil-nao-estao-no-litoral-e-sim-no-centro-oeste-mostra-ibge>. Acesso em: 23 mar. 2016.

PORTAL MATSUDA. A Produção de Tilápia no Brasil. Site. Disponível em: <http:// www.matsuda.com.br/matsuda/web/entrevistas/detalhe.aspx?idnot= H12101114130328\&lang=pt-BR>. Acesso em: 20 jun. 2016.

RAYOL, Marcus. A importância do plano de negócio para o sucesso do empreendimento. 2007. Site. Disponível em: < http://peritocontador.com.br/wp-content/uploads/2015/05/Marcus-Kleber-BentesRayol-A-Import\%C3\% A2ncia-do-Plano-de-Neg\%C3\%B3cio-para-o-Sucesso-doEmpreendimento.pdf >. Acesso em: 25 jul. 2016. 
RIBEIRO; Karina. Piscicultura sofre queda em Goiás. Site. 2015. Disponível em: <http:// www.opopular.com.br/editorias/noticias/economia/piscicultura-sofre-queda-em-goi\%C3\%A1s1.964353>. Acesso em: 16 ago. 2016.

RODRIGUES, Jorge Nascimento; et al. 50 Gurus Para o Século XXI. 1. ed. Lisboa: Centro Atlântico. PT, 2005.

SEITZ, Helgo. O planejamento estratégico de marketing e o Plano de Negócios. São Paulo: Pontifícia Universidade Católica de Santos. Revista Eletrônica de Gestão de Negócios. v. 1, n. 3, 2005, p.91-126.

SIDONIO, Luiza; et al. Panorama da aquicultura no Brasil: desafios e oportunidades. BNDES setorial: Agroindústria. Revista Agroindústria. n. 35 p. 421-463. 2012.

Recebido para publicação em 14/12/2016 e aprovado em 11/4/2017. 